\title{
ОБРАБОТКА ДЕТАЛЕЙ МЕТАЛЛООПТИКИ НА УЛЬТРАПРЕЦИЗИОННОМ СТАНКЕ «СФЕРА 100-Ф4"
}

\author{
Е. М. Захаревич, В. В. Лапшин, М.А. Шавва \\ АО «ВНИИИНСТРУМЕНТ», 04@vniiinstrument.ru, vasylap@mail.ru, Москва
}

\begin{abstract}
В статье представлены основные конструктивные особенности ультрапрецизионного станка для обработки металлооптических деталей, а также его технические и технологические характеристики. Описан процесс и основные особенности обработки оптической детали типа "Оболочка". Приведены результаты обработки пробной детали.
\end{abstract}

АО «ВНИИИНСТРУМЕНТ» последние несколько лет занимается разработкой и изготовлением современных ультрапрецизионных станков, предназначенных для обработки металлооптических изделий различной формы и назначения.

В рамках хозяйственного договора был создан ультрапрецизионный станок "Сфера 100-Ф4" для обработки металлооптических деталей методом алмазного точения и фрезерования (рис. 1). Данный станок предназначен для обработки плоских, осесимметричных, сферических, а также асферических поверхностей.

Основные конструктивные особенности станка «Сфера 100-Ф4» следующие:

- базовые элементы станка (станина, каретки, шпиндельная бабка) выполнены из натурального гранита;

- шпиндельный узел и поворотный стол станка выполнены с использованием сфе-

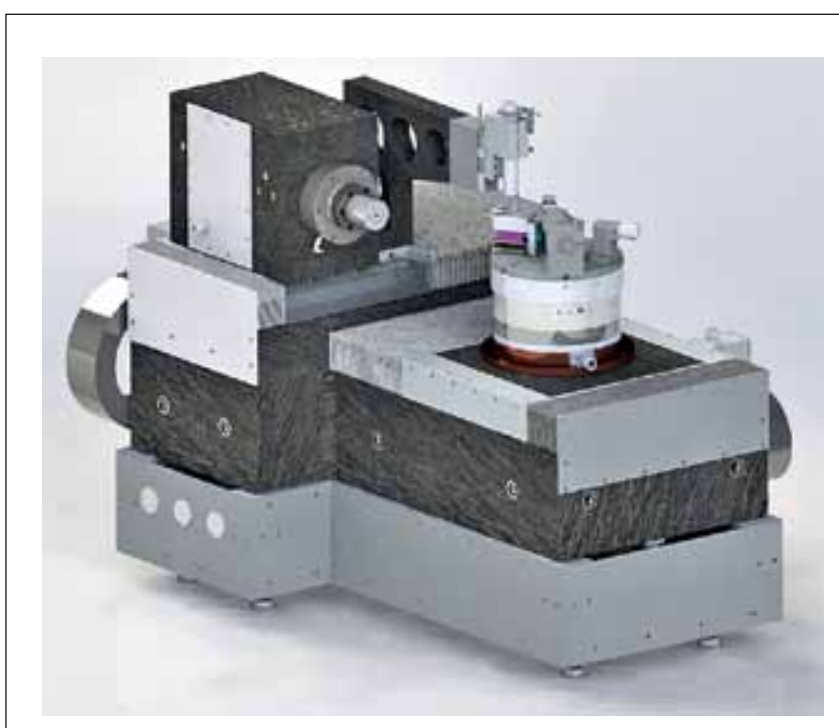

Puc. 1. Ультрапрецизионный станок для обработки оптических деталей рических аэростатических опор с пористым дросселированием;

- линейные узлы перемещений выполнены на аэростатических опорах с пористым дросселированием;

- станина станка установлена на специальных виброизолирующих пневматических опорах с собственной частотой менее 5 Гц;

- станок оснащен отечественными цифровыми комплектными электроприводами прямого действия.

- станок оснащен высокоскоростной аэростатической сверлильно-фрезерной головкой.

Технические и точностные характеристики станка “Сфера 100-Ф4" представлены в таблице 1 и таблице 2 соответственно.

Станок "Сфера 100-Ф4" оснащен отечественной специальной системой УчпУ с возможностью программирования линейных перемещений с дискретностью 1 нм. Реализована функция обмера и привязки инструмента с помощью оптического микроскопа.

Для устранения технологических погрешностей, которые могут возникнуть в процессе обработки, на станке предусмотрена процедура коррекции траектории движения инструмента. Для этой цели станок оснащен измерительным щупом с диаметром шарика 0,5 мм (рис. 2), который обмеряет обработанную поверхность после обработки. Точность срабатывания щупа по паспорту составляет $250 \mathrm{Hм}$, однако в условиях работы на станке "Сфера 100-Ф4", было установлено, что точность срабатывания щупа составляет 20-30 нм. Это обусловлено стабильностью скорости наезда щупа на исследуемую поверхность, а также механической точностью станка. Таким образом, станок "Сфера 100-Ф4" может выступать в качестве измерительной машины.

Процедура коррекции траектории движения инструмента состоит из следующих этапов: 
Таблица 1. Технические характеристики станка "Сфера 100-Ф4»

\begin{tabular}{|c|c|}
\hline Технические параметры & Значение \\
\hline Наибольшее перемещение поперечного суппорта, ось "X», мм & 400 \\
\hline Диапазон частот вращения шпинделя главного движения, ось "S", мин. ${ }^{-1}$ & $50-5000$ \\
\hline Диапазон частот вращения привода главного движения, ось “С”, мин. ${ }^{-1}$ & $0-200$ \\
\hline Диапазон рабочих подач продольного суппорта, ось "Z», мм / мин. & $0-200$ \\
\hline Диапазон рабочих подач поперечного суппорта, ось "X», мм / мин. & $0-200$ \\
\hline Диапазон рабочих подач поворотного стола, ось «В», мин. ${ }^{-1}$ & $0-10$ \\
\hline Дискретность задания перемещения продольного суппорта, мкм & 0,001 \\
\hline Дискретность задания перемещения поперечного суппорта, мкм & 0,001 \\
\hline Дискретность задания перемещения поворотного стола, ось "В», угл. сек & 0,0012 \\
\hline Дискретность задания перемещения круговой оси "С", угл. сек & 0,008 \\
\hline
\end{tabular}

- обработка оптической поверхности;

- обмер оптической поверхности непосредственно на станке с помощью щупа;

- построение полученной формы и сравнение ее с заданной;

- повторная обработка оптической поверхности с учетом коррекции погрешности формы;

Описанная процедура заложена в систему ЧПу и выполняется автоматически. Для достижения максимально возможной точности формы оптической поверхности возможно последовательное выполнение процедуры несколько раз.

По требованию заказчика на созданном ультрапрецизионном станке "Сфера 100-Ф4» была обработана оптическая деталь типа "Оболочка" с толщиной 0,3 мм в виде полусферы с радиусом 4,8 мм. Материал детали - бескислородная медь М0б. K детали были предъявлены следующие требования: точность формы внутренней сферы - 1 мкм, 


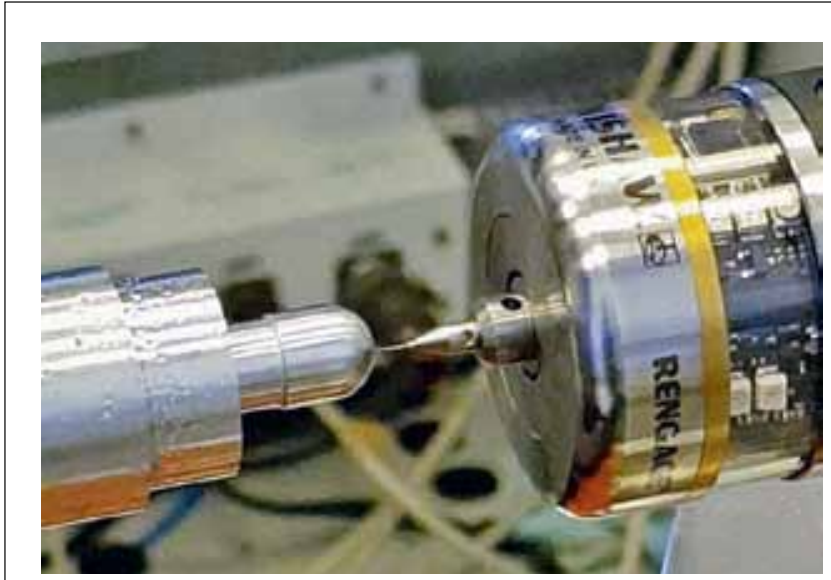

Puc. 2. Процесс обмера щупом обработанной поверхности

шероховатость поверхности внутренней сферы - Ra 0,01 мKм.

Для осуществления обработки был спроектирован и изготовлен комплект специального режущего инструмента, состоящий из алмазных и твердосплавных резцов (рис. 3). Алмазные резцы с радиусом 200-300 мкм использовались для чистовой обработки внутренней сферической поверхности, а резцы с радиусом 25-45 мкм предназначены для обработки выточки. Твердосплавные инструменты использовались для обработки наружной цилиндрической поверхности. Все резцы имели передний угол $\gamma=0^{\circ}$ и задний угол $\alpha=12^{\circ}$.

Для закрепления обрабатываемой детали на станке был разработан и изготовлен комплект оснастки, состоящий из двух оправок (рис. 4):

1) для базирования детали по внутренней сферической поверхности при обработке наружной сферы;

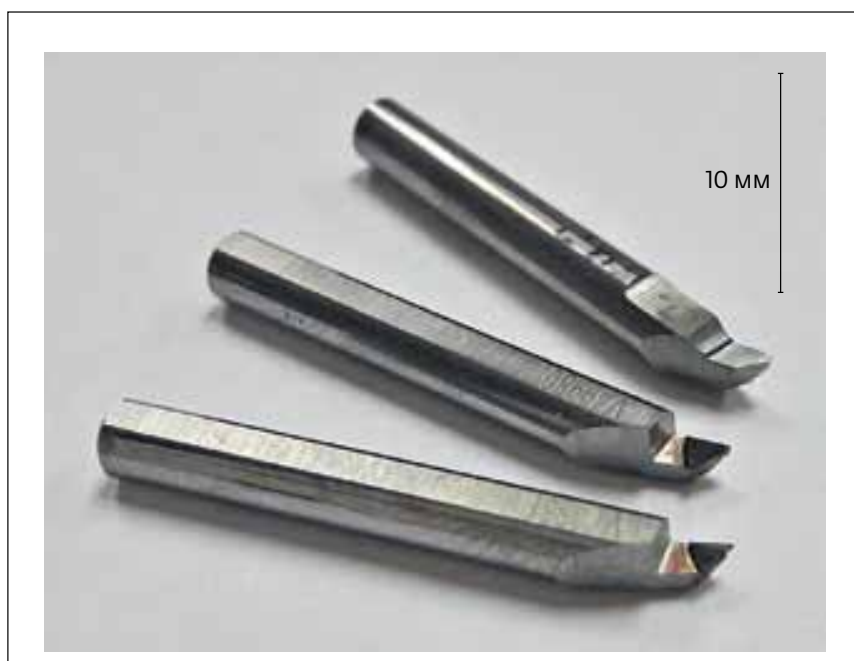

Puс. 3. Специальный режущий инструмент

2) для базирования детали по наружной сферической поверхности при обработке внутренней сферы;

Каждая оправка имеет в своем составе отверстия. Вакуумная станция создает в отверстиях оправок разрежение, которое позволяет удерживать заготовки во время обработки в определенном положении и с минимальными искажениями формы.

Обработка заготовок с припуском под окончательную обработку осуществлялась на прецизионном токарном станке.

На станке "Сфера 100-Ф4" реализована следующая последовательность процесса обработки детали типа "Оболочка":

1. Обработка наружной сферической поверхности и выточек твердосплавным резцом.

2. Обработка внеосевых отверстий.

3. Окончательная обработка выточек алмазным резцом и окончательная обработка наруж-

Таблица 2. Точностные характеристики основных узлов станка «Сфера 100-Ф4»

\begin{tabular}{|l|c|}
\hline \multicolumn{1}{|c|}{ Параметры } & 3начение \\
\hline Шпиндельглавного движения & $<50$ \\
\hline радиальное и осевое биение оси шпинделя главного движения, нм & 1 \\
\hline точность позиционирования круговой оси «С”, угл. сек. & $<$ \\
\hline Поворотный стол & $<50$ \\
\hline радиальное и осевое биение оси поворотного стола, нм & 1 \\
\hline точность позиционирования поворотной оси «В», угл. сек. & \\
\hline Продольный и поперечный суппорт & 0,5 \\
\hline прямолинейность перемещения суппорта оси «Z» (на длине 200 мм), мкм & 0,75 \\
\hline прямолинейность перемещения суппорта оси «Х» (на длине 400 мм), мкм & \\
\hline
\end{tabular}




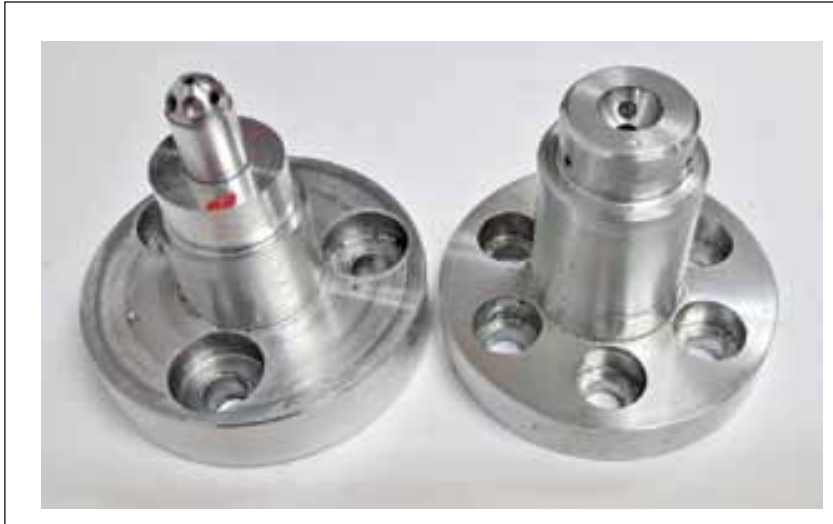

Puс. 4. Оснастка для закрепления детали на станке

ной сферической поверхности твердосплавным резцом с последующим обмером детали.

4. Установка на станок оснастки для обработки внутренней сферы и переворот детали.

5. Обработка внутренней сферической поверхности и выточек твердосплавным резцом.

6. Окончательная обработка выточек и внутренней сферической поверхности алмазным резцом с последующим обмером детали.

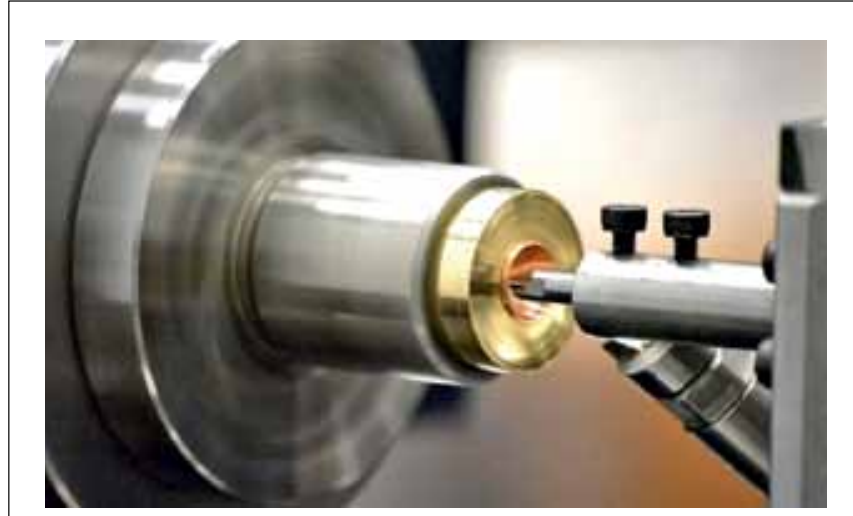

Puс. 5. Обработка внутренней сферической поверхности алмазным резцом

Результаты метрологического контроля показали, что шероховатость внутренней сферической поверхности после алмазного точения составила Ra 0,01-0,011 мкм. Точность формы внутренней сферической поверхности после точения твердосплавным резцом составила 2-3 мкм. Результаты по точности формы, полученные после обработки алмазным резцом, будут получены в ближайшее время. 